\title{
Atributos críticos de satisfação em serviços de arquitetura: visão do cliente $\times$ visão do arquiteto
}

\author{
lsabela Winter Almada ${ }^{a *}$, Gérson Tontini ${ }^{\mathrm{b}}$ \\ a*bela@tao.arq.br, Tao Arquitetura, Brasil \\ bgersontontini@gmail.com, FURB, Brasil
}

\begin{abstract}
Resumo
0 presente trabalho tem por objetivo identificar se a percepção sobre os atributos necessários para a satisfação do cliente em projetos residenciais (construção ou reformas) são os mesmos entre clientes e arquitetos. Trata-se de uma pesquisa quantitativa exploratória, que emprega questionários estruturados não disfarçados como instrumento de coleta de dados. Os 15 atributos pesquisados foram definidos por meio da literatura. A coleta de dados foi realizada com 100 clientes pessoas físicas e 30 profissionais. Os resultados da pesquisa indicam que os clientes esperam que o arquiteto resolva o seu problema e consiga entender as suas necessidades, sem necessidade de alterações ou muitas interações com o cliente. Na visão dos clientes, o serviço a ser prestado pelos arquitetos é um serviço técnico. Já os arquitetos percebem que o serviço deve ser construído em conjunto com o cliente e que seu serviço está mais concentrado na criação, no design. Como conclusão, levando em conta a visão dos clientes, o escritório de arquitetura que quiser ter um diferencial competitivo deve entender que seu serviço engloba desde a criação até a entrega da obra, com garantia dos serviços prestados. Deve entender também que o cliente pressupõe que o arquiteto deve saber de suas necessidades e que o atendimento ao cronograma e orçamento iniciais são atributos atrativos.
\end{abstract}

Palavras-chave

Qualidade em serviços. Satisfação do cliente. Qualidade em serviço de arquitetura.

\section{Introdução}

A busca por novos mercados e a inserção e estabilização de novas empresas nestes mercados apontam como ponto nevrálgico o cliente. A competitividade e a dinâmica do mundo atual fazem com que as organizações se atualizem constantemente, em busca da satisfação de seus clientes. Em função disto, aumenta a cada dia a atenção dada à qualidade dos serviços, o que mobiliza muitos gestores de organizações voltadas a serviços.

Nos últimos anos os escritórios de arquitetura nacionais começaram a se preocupar com a concorrência de escritórios estrangeiros, que ligados a projetos comerciais e de empreendimentos de lazer, vêm pressionando os escritórios locais no que se refere às limitações técnicas e organizacionais. (MELHADO et al., 2003). Além da entrada de concorrentes internacionais, os escritórios de arquitetura estabelecidos têm enfrentado um grande aumento na concorrência, devido à entrada de novos profissionais no mercado de trabalho. Em 2007, o Brasil formou 6.701 novos Arquitetos, 52\% a mais que os formados em 2001 (INSTITUTO..., 2001, 2007).

Essa concorrência fez com que os profissionais se sentissem obrigados a buscar uma melhoria da qualidade dos seus serviços e a satisfação de seus clientes. A preocupação se volta cada vez mais em encontrar quais atributos de um serviço são realmente relevantes para os clientes, qual o retorno imediato e de longo prazo que esses atributos trarão para o escritório e também para aumentar a lealdade dos clientes. Clientes leais divulgam positivamente os trabalhos do arquiteto, o que leva à conquista de mais clientes (TORBICA; STROH, 2000). Durante vários anos 0 arquiteto se considerava um artista, contratado para conceber uma obra de arte, incontestável e indiscutivel, destinada a durar "para sempre" (POWELL, 1987, 
p. 84). Porém, com o aumento da competição, os escritórios de arquitetura devem procurar satisfazer as necessidades dos clientes, como em qualquer outro serviço, mesmo sendo um serviço que envolva "criação e arte". Symes, Eley e Seidal (1995) concluíram em seu estudo que, para sobreviver, os arquitetos devem aprender a se adaptar às necessidades dos clientes.

Conhecer as necessidades dos clientes de projetos de arquitetura residenciais (construção ou reforma) e quais são os atributos de determinado serviço que mais os satisfazem é um dos pontos abordados neste trabalho. Comparar essas necessidades e requisitos, com o que o profissional arquiteto considera como atributos de sucesso é o foco da pesquisa a seguir.

Baseado no fato de que para se manter no mercado nos dias atuais temos que ter como foco principal o cliente, os escritórios de arquitetura têm se preocupado cada vez mais com o atendimento de seus clientes e com a superação das expectativas deles em relação ao projeto. Os atributos básicos de um serviço de arquitetura, tais como qualidade no projeto e seus detalhamentos, já não são mais um diferencial, e sim características básicas para um serviço de arquitetura. 0 que pode fazer a diferença para esse serviço, muitas vezes, é saber quais atributos são imprescindíveis para um serviço perfeito na visão do cliente, e então trazê-los ao encontro dos atributos satisfatórios na visão do arquiteto.

Apesar de existirem muitos estudos sobre satisfação de clientes, pouco foi pesquisado sobre quais são os atributos ou características de satisfação para o cliente de projetos de arquitetura residenciais e quais são esses atributos na visão dos arquitetos. Se, ao final de um projeto, ambos falaram a mesma linguagem e superaram suas expectativas, o sucesso do projeto será completo, tanto por parte do cliente (usuário) como por parte do arquiteto idealizador do projeto.

Acredita-se que um dos fatores mais relevantes que impedem o bom desenvolvimento de um projeto e a plena satisfação do cliente ao final desse processo é o fato de normalmente o escritório de arquitetura não identificar com clareza quais elementos e funções efetivamente compõem o serviço, e quais fatores realmente são avaliados pelos clientes em cada uma das funções que o serviço oferece. Assim, o objetivo deste trabalho é identificar a percepção dos clientes e dos arquitetos quanto aos atributos necessários à prestação de serviços vinculados aos escritórios de arquitetura, observando se os atributos críticos de satisfação são os mesmos atributos ou se existem diferenças de percepção entre clientes e arquitetos. É nesse contexto que a realização do presente trabalho torna-se relevante, pois possibilita aos profissionais tomarem decisões voltadas à melhoria da qualidade do serviço segundo a ótica dos clientes.

\section{Revisão da literatura sobre qualidade em serviços de arquitetura}

Melhado et al. (2003) apresentam em seu artigo uma amostra da qualidade dos serviços de arquitetura na cidade de São Paulo. A pesquisa foi realizada com empresas que participavam de um programa de qualidade no desenvolvimento de projeto, promovido por entidades de classe ligadas a esse setor. A análise dos resultados mostrou mudanças significativas nos processos técnicos dos escritórios, contribuindo para uma melhor padronização dos processos e melhor entrega do produto final ao cliente. Mas as alterações de projeto pela interface com demais projetistas ou mesmo do programa de necessidades por parte do cliente, ocasionando um maior retrabalho e atrasos nos prazos de entrega, foram citadas como entrave para a implantação dos processos de qualidade. Deficiências nos processos comerciais e administrativos, tais como estratégias competitivas, segmentação de mercado e avaliação sistemática da satisfação do cliente, também foram citadas, mostrando a falta de visão do arquiteto em relação à estabilidade do escritório no mercado atual. Algumas empresas ainda entendem o projeto como produto, finalizado quando entregue ao cliente, sem nenhuma preocupação com a retroalimentação e a necessidade de melhorias contínuas.

As mudanças que vêm acontecendo nos últimos anos, no mercado dos serviços, têm feito com que as empresas pensem um pouco mais sobre seu público alvo. Os arquitetos e construtores não são exceções. Morgan, Foreman e Poh (1994), em seu artigo sobre marketing em escritórios de arquitetura, comentam que, somente nos últimos anos, as empresas de arquitetura têm pensado efetivamente em marketing, e mesmo assim com foco no anúncio e promoção, e não no desenvolvimento ou lançamento de novos serviços. A pesquisa foi realizada em empresas de grande porte de serviços de arquitetura do Reino Unido. Ao final da análise a pesquisa mostra que a implantação do marketing acontece nessas empresas de maneira reativa e não pró-ativa.

A necessidade de contratar o serviço de um arquiteto, especialmente entre pessoas da classe média, vem se tornando cada vez mais comum atualmente. Mas essa decisão de contratar, e a expectativa da escolha do profissional, do projeto e da obra, tornam essa tarefa complicada para o cliente. Em seu artigo, Winters (2003) nos mostra o resultado de um Fórum de Proprietários, organizado pelo Instituto Americano de Arquitetura (AIA), reunido para descobrir ou reforçar o que os proprietários desejam dos arquitetos e como atingir suas expectativas. Como resultado, foram propostos oito pontos a serem seguidos pelos proprietários ao contratar os serviços de arquitetura. 
Entre esses pontos, foram analisados o contrato com os profissionais, quais os deveres e direitos tanto do profissional quanto do proprietário da obra, divergências entre o arquiteto e o executor da obra e também sobre a matriz de necessidades do projeto, que foi enfatizada como uma das partes mais importantes para o êxito do projeto.

Uma das fases consideradas importantes em um projeto de arquitetura é o briefing, que resultará no "programa de necessidades" do projeto a ser executado, com os desejos, expectativas, ideias e necessidades, que o cliente deve passar para o arquiteto antes do início do projeto. Pode ser realizado de várias maneiras, mas principalmente em reuniões com o cliente e, se possível, não somente numa reunião, pois é nessa fase que o arquiteto tem que captar todas as informações sobre o projeto antes de iniciar os trabalhos. Othmann, Hassan e Pasquire (2005) falam da importância do desenvolvimento do briefing do projeto durante o ciclo do projeto. Depois do primeiro briefing feito, inicia-se o projeto e durante esse desenvolvimento muitas coisas mudam, por vontade do cliente ou muitas vezes por problemas técnicos, e na maioria das vezes não se faz a atualização desses dados. Os autores mostram a necessidade do contínuo desenvolvimento do briefing para: um melhor acompanhamento do projeto pelo cliente e pelo arquiteto; corrigir erros no briefing inicial; corrigir falta de dados ou documentos e para pontuar problemas que sirvam de lição para problemas futuros. A pesquisa mostrou também que esse sistema pode ter um lado negativo, trazendo mais retrabalho aos documentos do projeto, mais supervisão por parte do escritório, atrapalha toda a programação de trabalho já feita, e pode gerar desavenças entre as partes.

Faulkner, Hudson e Barrett (2000) em seu artigo sobre qualidade na construção, falam da necessidade de mudanças na indústria da construção, indicando a necessidade de se focar cada vez mais no cliente. A pesquisa foi feita com clientes profissionais (empresas privadas e estatais) e empresas construtoras (consultores) escolhidas por esses clientes como empresas com serviço exemplar. Cada uma dessas empresas construtoras escolheu dois projetos para serem utilizados em um estudo de casos. A análise dos dados mostrou que a qualidade é uma questão importante para ambos, clientes e empresas profissionais. Entretanto, os clientes preferem fazer seu próprio julgamento sobre a qualidade, não se importando com sistemas de qualidade formais. E os consultores destas empresas profissionais que possuem algum sistema de qualidade implantado, fizeram isso por pressão do mercado, não como um instrumento de gerenciamento. Eles mostram também que o cliente se preocupa muito na escolha destes consultores, mas que após escolhidos eles acreditam que o consultor guiará todo o processo e o resultado deverá ser satisfatório. E, principalmente, concluem que o briefing é a chave para serviços exemplares. Mas existe uma contradição nesse ponto, pois os clientes não reconhecem o briefing como um esforço necessário ao sucesso do projeto, já os consultores o consideram crucial.

A pesquisa dos autores Cheng, Proverbs e Oduoza (2006) é uma grande investigação sobre clientes da construção civil. 0 foco foi empreender um profundo estudo sobre níveis de satisfação do cliente e então usar esses resultados para identificar maneiras de melhorar os serviços fornecidos por consultores. Neste caso, consultores são todos os profissionais envolvidos na construção, desde arquitetos, construtores, engenheiros, etc. A análise dos dados revelou que a qualidade total dos serviços, a exatidão técnica e o pessoal (equipe de funcionários do consultor) são os atributos de desempenho-chave para consultores na percepção dos clientes. Os clientes consideram comunicação eficaz e seus fornecedores de serviço como sendo os mais importantes critérios ao determinarem seus níveis da satisfação. Além disso, o desempenho total dos consultores nestas áreas-chave e as decisões estratégicas do cliente fazem uma contribuição significativa para a satisfação do cliente.

A união de bom projeto e boa execução também é uma questão importante a ser estudada. Para que o cliente sinta-se satisfeito, o produto final tem que estar perfeito. Para isso várias etapas são percorridas entre projeto e obra. Essa ligação entre os profissionais envolvidos é muito importante para o bom andamento do projeto, pois o trabalho de um interfere profundamente no trabalho do outro. Muitas vezes, é nesse intervalo que acontecem os problemas, e o cliente não sabe como resolver.

Soetanto, Proverbs e Holt (2001) mostram com sua pesquisa a necessidade de um bom relacionamento entre os profissionais envolvidos em um projeto. 0 contexto desta pesquisa se baseia na visão do cliente e do arquiteto a respeito do desempenho do construtor no Reino Unido, e quão importante é esse relacionamento para se alcançar a qualidade do projeto final. Ao final da pesquisa, os autores mostraram que cliente e arquiteto têm basicamente a mesma opinião sobre o construtor, e que os requisitos considerados mais importantes para o bom desempenho do construtor são fidelidade ao orçamento e espírito de colaboração de sua equipe. Honestidade, integridade e o compromisso das pessoas envolvidas foram considerados os requisitos de melhor desempenho pelos clientes e arquitetos, respectivamente. E um dado bastante importante é que o requisito considerado como prioridade para melhoria é a conclusão dos 
defeitos, ou seja, reparos de defeitos após a conclusão e entrega da obra. No geral os clientes e arquitetos possuem as mesmas opiniões sobre o construtor, havendo pequenas diferenças em alguns critérios, pois 0 arquiteto prima principalmente pela qualidade, e que a obra final fique exatamente dentro dos padrões desenhados por ele. E o cliente prima pelo cronograma e orçamento, que são os critérios que o afetam diretamente.

De acordo com a literatura acima pesquisada, o Quadro 1 mostra os atributos específicos aos serviços de arquitetura e construção, mostrando os autores dos artigos e os atributos retirados das conclusões de suas pesquisas.

\section{Qualidade em projetos de arquitetura residenciais}

Os conceitos e metodologias de gestão da qualidade foram desenvolvidos em geral em setores da indústria de transformação. Embora guarde relação com as indústrias manufatureira e de transformação, a construção civil apresenta uma estrutura de produção bastante diferente destes setores, inclusive no que diz respeito à utilização dos conceitos de qualidade. lsso se reflete na obra civil no que se refere à baixa produtividade, a altos índices de desperdício e problemas de qualidade (PICCHI, 1993). Cornik (apud MUNTING; CRUYWAGEN, 2008) cita que dois estudos independentes conduzidos no Reino Unido concluíram que 33 a 50\% das falhas na indústria da construção foram atribuídas ao projeto arquitetônico.
Como uma boa parte da obra civil refere-se à fase de produção (construção), na construção civil, tradicionalmente, a qualidade é definida como "conformidade com as especificações", ou seja, quanto a construção ficou de acordo com o projeto (TORBICA; STROH, 1999). Segundo Kärnä (2004), o problema com essa abordagem é que ela é centrada internamente, pois os clientes podem não se importar quanto o produto/serviço está em conformidade às especificações internas. Segundo este autor, o que os clientes querem é que suas necessidades sejam atendidas ou excedidas. Segundo Torbica e Stroh (1999, p. 333), enquanto a definição de qualidade como "conformidade aos requisitos" é apropriada para a fase de construção, ela é problemática para a fase de design, a qual, por natureza, requer muito mais "julgamento, discrição e criatividade". Assim, a qualidade na construção civil deve ser abordada de diferentes aspectos, dependendo da fase que se encara. 0 projeto arquitetônico é, na verdade, um serviço ao cliente.

A literatura sobre qualidade em serviços mostra que as expectativas dos clientes desempenham um papel muito importante na avaliação de uma empresa. Os clientes avaliam a qualidade do serviço fazendo comparações entre o que esperavam com o que foi obtido (BERRY; PARASURAMAN, 1992). Sendo assim, a qualidade é subjetiva, pois é relativa e definida em função do que cada cliente espera. Por isso, as expectativas desempenham papel fundamental na avaliação da qualidade do serviço. Os autores ainda fazem uma observação importante, dizendo que a expectativa tem sido utilizada em dois sentidos:

Quadro 1. Atributos de serviços de arquitetura segundo a literatura pesquisada.

\begin{tabular}{|c|c|c|c|c|c|c|c|}
\hline & 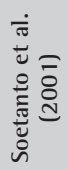 & 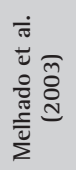 & 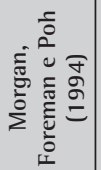 & 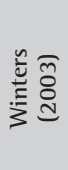 & 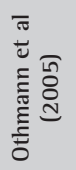 & 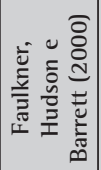 & 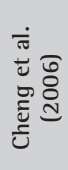 \\
\hline \multicolumn{8}{|l|}{ Fidelidade ao orçamento } \\
\hline \multicolumn{8}{|c|}{ Espírito de colaboração da equipe de profissionais envolvida no projeto } \\
\hline \multicolumn{8}{|c|}{ Honestidade, integridade e compromisso do profissional } \\
\hline \multicolumn{8}{|l|}{ Garantia dos serviços } \\
\hline \multicolumn{8}{|c|}{ Flexibilidade para alterações na obra/ programa de necessidades } \\
\hline \multicolumn{8}{|c|}{ Treinamento e empatia da equipe de contato com cliente } \\
\hline \multicolumn{8}{|l|}{ Exatidão técnica (confiabilidade) } \\
\hline \multicolumn{8}{|c|}{ Direitos e deveres no contrato cliente/profissional } \\
\hline \multicolumn{8}{|l|}{ Programa de necessidades do projeto } \\
\hline \multicolumn{8}{|c|}{ Desenvolvimento contínuo do programa de necessidades } \\
\hline \multicolumn{8}{|l|}{ Sistemas de qualidade implantados } \\
\hline \multicolumn{8}{|l|}{ Fidelidade ao cronograma } \\
\hline \multicolumn{8}{|l|}{ Comunicação profissional/cliente } \\
\hline Profissional com bons fornecedores & & & & & & & \\
\hline
\end{tabular}


primeiro no sentido daquilo que os clientes acreditam que ocorrerá quando se deparam com o serviço e em segundo, no sentido daquilo que os clientes desejam que ocorra. Um serviço será considerado de excelência se superar o que os clientes esperam, indo ao encontro do desejado.

Considerando as características peculiares dos serviços, como o fato de serem intangiveis e perecíveis, a qualidade torna-se difícil de ser avaliada quando comparada à dos produtos manufaturados. Por isso, a qualidade deve ser avaliada sob o ponto de vista do cliente e deve ser dividida em determinantes que facilitem a compreensão do seu significado. Parasuraman, Zeithaml e Berry (1985) reúnem esses determinantes, ou atributos, em cinco dimensões: confiabilidade, responsividade, segurança, empatia, tangíveis. Porém, para cada tipo de serviço poderá existir um conjunto específico de determinantes da qualidade que atenda a essas dimensões (GIANESI; CORRÊA, 1996).

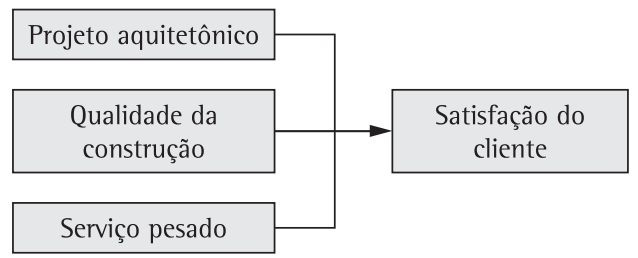

Figura 1. Dimensões da satisfação em projetos residenciais. Fonte: adaptado de Torbica e Stroh (2000).
Torbica e Stroh (2000) propõem que a qualidade de um projeto residencial deve ser medida pela satisfação do cliente, determinada pelo desempenho da qualidade final da construção, seu projeto arquitetônico e pelos serviços associados (Figura 1).

A dimensão "Projeto" inclui determinantes sobre a funcionalidade e estética do projeto arquitetônico. A dimensão "Construção" inclui os atributos da qualidade final do acabamento da construção e seus defeitos. A dimensão "Serviço" inclui aspectos de comunicação sobre o projeto arquitetônico e a obra, acessibilidade, cordialidade, empatia, confiabilidade, responsividade e competência do pessoal envolvido na construção e no projeto. Torbica e Stroh (2000) concluíram que a dimensão serviço é a que mais influencia na satisfação do cliente $(r=0,777)$, seguida da qualidade da construção $(r=0,754)$ e, por último, o projeto arquitetônico em si $(r=0,578)$.

A importância das dimensões, encontrada no trabalho de Torbica e Stroh (2000), foi efetuada após a realização dos serviços. Devido à longa duração dos projetos de construção civil, Forsythe (2008), baseado no modelo de gaps de Parasuraman, Zeithaml e Berry (1985), propõe que a satisfação final dos clientes de projetos residenciais se dá pela confirmação ou desconfirmação de suas expectativas durante as diversas fases do projeto (Figura 2). 0 autor propõe que a qualidade do serviço será avaliada pelas dimensões confiabilidade, responsividade, segurança, empatia, tangiveis, (PARASURAMAN; ZEITHAML; BERRY, 1985), estética do projeto, qualidade técnica do acabamento e fidelidade da obra ao projeto arquitetônico.

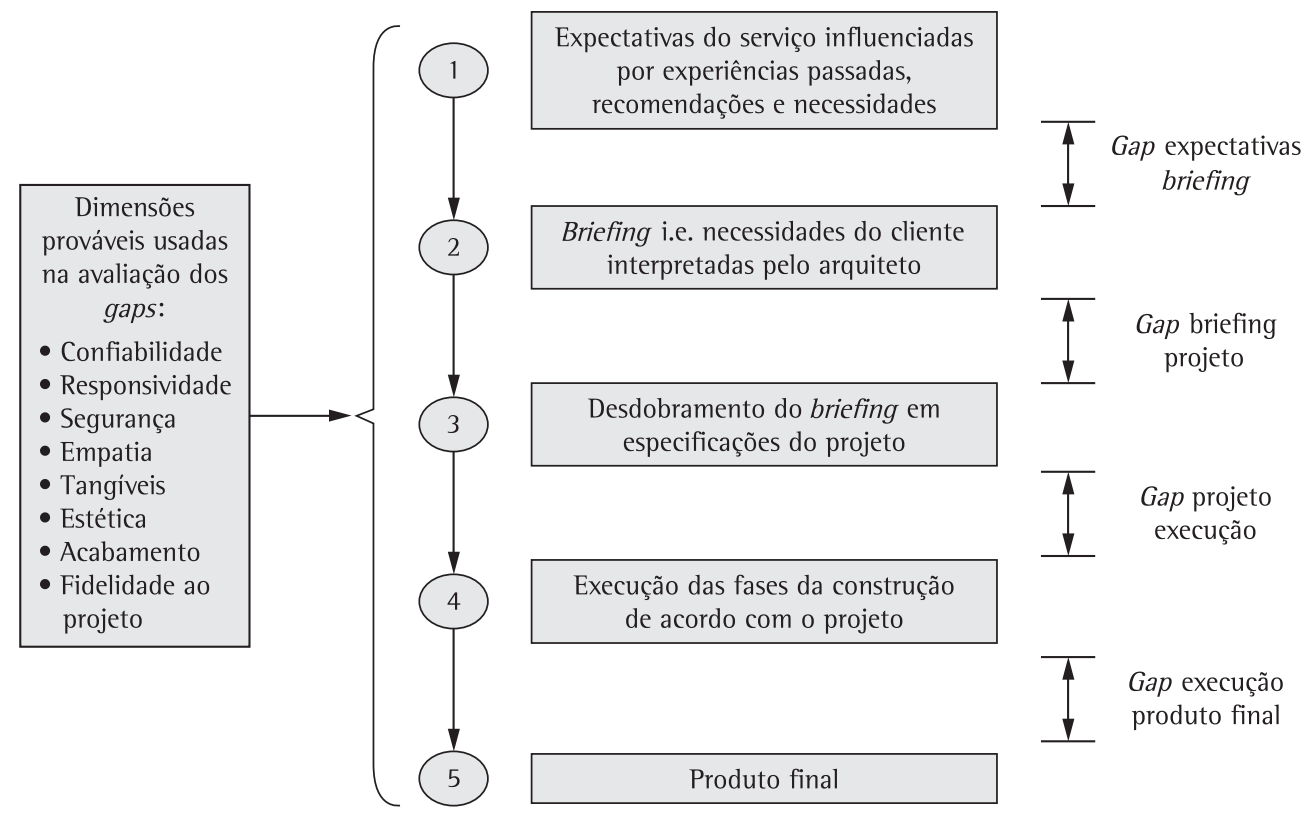

Figura 2. Fases e gaps de expectativas em projetos de construção. Fonte: Adaptado de Forsythe (2008). 
0 Arquiteto contratado por uma pessoa física para elaboração do projeto de construção ou reforma de uma residência é responsável por identificar as necessidades do cliente e traduzi-las em características do projeto. Em muitos casos, ele deve supervisionar os trabalhos de construção, inclusive indicando fornecedores. Assim, a avaliação da qualidade dos serviços de arquitetura deve incluir a satisfação do cliente durante a fase de construção.

\section{Metodologia da pesquisa}

Esta pesquisa configura-se como do tipo quantitativa e exploratória. Segundo Gil (2007), as pesquisas exploratórias têm como principal propósito desenvolver, esclarecer e modificar conceitos e ideias, tendo em vista a formulação de problemas mais precisos ou hipóteses pesquisáveis para estudos posteriores. Para atingir os objetivos propostos, este trabalho seguiu os seguintes passos: pesquisa bibliográfica, pesquisa documental e pesquisa de campo. Com base na revisão da literatura da área, o Quadro 2 mostra os atributos que foram escolhidos para fazerem parte dos questionários da pesquisa:

0 objeto de estudo foi os serviços de projetos residenciais (construção ou reforma) contratados por pessoas físicas. 0 universo compreende então todos os arquitetos que prestam esse tipo de serviço e pessoas físicas que os contratam.
A amostra utilizada nesta pesquisa foi formada pelos profissionais que participaram da Mostra Casa \& Cia 2007, de Blumenau - SC, e os clientes destes profissionais, pessoas físicas, que foram atendidos e com projetos concluídos nos últimos doze meses anteriores à pesquisa. A escolha desta amostra ocorreu por ser um evento de grande importância e credibilidade na cidade, que integra alguns dos melhores profissionais de todo o Vale do ltajaí e litoral. A escolha de clientes dos mesmos profissionais entrevistados deve-se ao fato de se querer perceber as diferenças de percepção entre eles. Assim, entrevistar clientes e fornecedores dos mesmos serviços permite a verificação dessas diferenças (se existirem) com uma amostra menor que a que seria necessária para uma ampla pesquisa descritiva no setor. Devido à metodologia e amostragem utilizada, os resultados não devem ser generalizados, sendo válidos apenas para a amostra pesquisada.

Foram entregues 300 questionários a clientes, dos quais 113 foram respondidos, e somente 100 puderam ser utilizados por motivos de rasuras e inexistência de respostas. Entre os 42 profissionais que participaram da Mostra Casa \& Cia, três pediram para não participar da pesquisa. Dos demais, se obteve 30 respondentes.

0 questionário de pesquisa, adaptado a partir das contribuições de Tontini e Sant'Ana (2007), foi composto de quatro partes. Na primeira, os respondentes avaliaram sua satisfação com situações

Quadro 2. Atributos dos serviços de arquitetura escolhidos para serem pesquisados e seus significados.

\begin{tabular}{|c|c|}
\hline Atributos pesquisados & Significados \\
\hline Fidelidade ao orçamento & Capacidade do profissional de executar os serviços dentro do valor originalmente previsto (projeto e obra) \\
\hline Empatia - entrosamento com cliente & Capacidade de encantar o cliente em cada contato seu com o profissional \\
\hline Confiabilidade - capacidade técnica & Capacidade do profissional em transmitir segurança ao cliente \\
\hline \multirow{2}{*}{ Garantia dos serviços prestados } & Habilidade de solucionar problemas durante a obra, compatibilização entre projetos \\
\hline & Garantia que após a entrega da obra, possíveis defeitos sejam corrigidos rapidamente \\
\hline \multirow{2}{*}{ Flexibilidade } & Capacidade do profissional de alterar os projetos ou especificações por problemas técnicos ou financeiros \\
\hline & Capacidade do profissional de alterar os projetos por motivo de mudança no programa de necessidades \\
\hline \multirow{3}{*}{ Acesso ao profissional } & Oferecer ao cliente horário de atendimento de acordo com a sua necessidade \\
\hline & Contato direto com o profissional \\
\hline & Fácil acesso ao escritório do profissional \\
\hline Interesse pelo cliente & $\begin{array}{l}\text { Demonstrar interesse pelo cliente através dos cuidados com os mínimos detalhes que o envolvem ao } \\
\text { projeto e ocupação }\end{array}$ \\
\hline Interação do cliente com o processo & Manter o cliente informado de todo andamento do processo do serviço \\
\hline Entender as necessidades do cliente & $\begin{array}{l}\text { Saber extrair as informações do cliente com extrema clareza para a confecção de um programa de } \\
\text { necessidades completo }\end{array}$ \\
\hline \multirow{2}{*}{ Velocidade no atendimento } & Tempo de atendimento adequado às necessidades do cliente \\
\hline & Reuniões com o cliente dentro dos prazos estipulados \\
\hline Comunicação (projeto) & Entregar ao cliente projetos com todas as informações necessárias e de forma que o cliente entenda \\
\hline Fidelidade ao cronograma & Seguir o cronograma da obra no caso do acompanhamento \\
\hline Preço & Valor cobrado pelo arquiteto \\
\hline Acompanhamento da obra & Acompanhamento da obra após o projeto \\
\hline Qualidade do projeto final & Funcionalidade e qualidade do projeto final \\
\hline
\end{tabular}

Fonte: autores. 
imaginárias de suficiência e insuficiência no desempenho de cada atributo em um questionário modificado do Modelo Kano (KANO et al., 1984). Tontini e Sant'Ana (2007) propõem um questionário utilizando uma escala variando de -3 (muito insatisfeito) a +3 (muito satisfeito) para cada resposta. Para evitar simetria nas respostas, as perguntas positivas e negativas foram dispostas em ordem aleatória no questionário. Em seguida, a importância de cada atributo foi avaliada em uma escala de 1 a 5 , sendo 1 "sem importância" e 5 "extremamente importante". Na terceira parte, usando a mesma escala da parte 1, pediu-se aos respondentes que marcassem sua satisfação com o desempenho atual dos atributos pesquisados no último serviço de arquitetura contratado. Por último, pediu-se a satisfação geral com o último serviço de arquitetura que utilizou e alguns dados demográficos. No caso dos profissionais entrevistados, pediu-se a eles para responder as questões avaliando como eles imaginam seria a satisfação dos clientes em cada situação de suficência e insuficiência dos atributos, a satisfação atual dos clientes e o grau de importância que os clientes dão a cada atributo.

Para verificar as diferenças de percepção entre os dois grupos de respondentes, a análise dos dados foi realizada pela Matriz de Importância $\times$ Desempenho (MARTILLA; JAMES, 1977) e pela Análise dos Gaps de Melhoria (TONTINI; SANT'ANA, 2007).

A Matriz de importância e desempenho, proposta por Martilla e James (1977), permite uma visão sobre quais atributos de serviço deveriam ser melhorados para tornarem-se mais competitivos no mercado. Os dados pesquisados são utilizados para construir uma matriz bi-dimensional, na qual a importância é mostrada pelo eixo y e o desempenho do atributo pelo eixo x. A matriz é dividida em quatro quadrantes: o Quadrante 1 mostrará atributos com alta importância e alto desempenho, representando uma possível vantagem competitiva; no Quadrante 11, atributos com alta importância, mas baixo desempenho, que deverão receber atenção imediata; o Quadrante 111 contém os atributos com baixa importância e baixo desempenho, não sendo necessário concentrar esforço adicional; e o Quadrante IV apresenta os atributos com alto desempenho, porém com baixa importância, neste caso o profissional pode estar desperdiçando recursos que poderiam ser mais bem aproveitados com outras aplicações. Apesar de amplamente utilizada, a matriz de importância e desempenho tem como pressupostos a independência entre essas duas dimensões e que o desempenho dos atributos influencia de forma linear a satisfação dos clientes. Estes pressupostos podem levar a decisões errôneas na hora de se identificar oportunidades de melhoria (HUISKONENN; PIRTILLÄ, 1998)
O Modelo Kano de Qualidade Atrativa e Obrigatória (KANO et al. 1984; BERGER et al., 1993; MATZLER et al., 1996) traz uma perspectiva diferente para a análise de oportunidades de melhoria, levando em consideração a relação assimétrica entre desempenho e satisfação. 0 Modelo Kano faz distinção entre três tipos de atributos que influenciam a satisfação do cliente: atrativos, obrigatórios, unidimensionais, neutros e reversos. Apesar de o Modelo Kano trazer essa visão diferente sobre o efeito do desempenho dos atributos na satisfação do consumidor, ele não leva em consideração o nível atual de desempenho deles. Como a posição competitiva não é levada em consideração, o Modelo Kano, usado de maneira isolada, também é limitado como um direcionador dos esforços de melhoria (TONTINI; SILVEIRA, 2007). Na Matriz de Análise dos Gaps de Melhoria, integram-se os modelos Kano e Importância x Desempenho, mudando a maneira de atribuir os valores no eixo de desempenho. No eixo x é plotado o gap positivo, dado pela subtração da satisfação atual com o atributo da satisfação esperada com a suficiência do atributo (situação desejada - atual). A importância declarada é plotada no eixo y. Foi escolhida a importância declarada pelo fato de ela permitir uma melhor visualização dos atributos atrativos, que tendem a ter baixa importância declarada (SAUERWEIN, 1999; TONTINI; SILVEIRA, 2007). Nesse caso, quanto maior o gap de desempenho, mais distante está o desempenho atual do atributo do que seria a situação ideal. Com isso, atributos com baixa importância e gap elevado são considerados atrativos, ao invés de pontos fracos menores como na matriz de importância e desempenho original. Atributos com alta importância e com grande gap de melhoria representam atributos críticos para melhoria. Atributos com grande importância declarada, mas com baixo gap, são considerados básicos. Atributos com baixo gap de melhoria e baixa importância são considerados neutros.

Neste trabalho, as linhas divisórias dos quadrantes foram efetuadas pela média do desempenho e da importância, tanto para a análise do gap de melhoria quanto para a análise de importância e desempenho.

\section{Resultados da pesquisa}

Na amostra de clientes pesquisada, $80 \%$ dos entrevistados tinham entre 25 e 45 anos e $20 \%$ entre 46 e 65 anos de idade. Destes, $67 \%$ eram mulheres e 33\% homens. Entre os clientes, 28\% contrataram os serviços de profissionais uma vez e $23 \%$ duas vezes antes. Em média, os clientes entrevistados já contrataram os serviços de arquitetos 2,5 vezes antes da entrevista. 
Já entre a amostra dos profissionais pesquisados, $70 \%$ têm idade entre 20 e 35 anos e 30\% têm idade entre 36 e 50 anos. Entre os profissionais pesquisados, $74 \%$ são mulheres e 26\% são homens, e existe uma igualdade entre os profissionais no que diz respeito ao estado civil deles. Os profissionais pesquisados têm em sua maioria mais de 5 anos de profissão, mas possuem escritórios pequenos, com menos de 5 pessoas trabalhando.

\subsection{Atributos críticos de satisfação na visão dos profissionais}

Inicialmente serão analisados os gráficos dos modelos de avaliação citados acima, de acordo com os dados dos questionários respondidos pelos profissionais sobre o que pensam que seu cliente sente em relação aos serviços de arquitetura. Os atributos foram classificados de acordo com a matriz de Importância $\times$ Desempenho (Figura 3) e matriz de Análise de Gaps de Melhoria (Figura 4).

A Figura 3 mostra que, na visão dos arquitetos, seus serviços apresentam melhor desempenho naqueles atributos que os clientes consideram como mais importantes. Entre os atributos pesquisados, os profissionais consideram que têm um desempenho

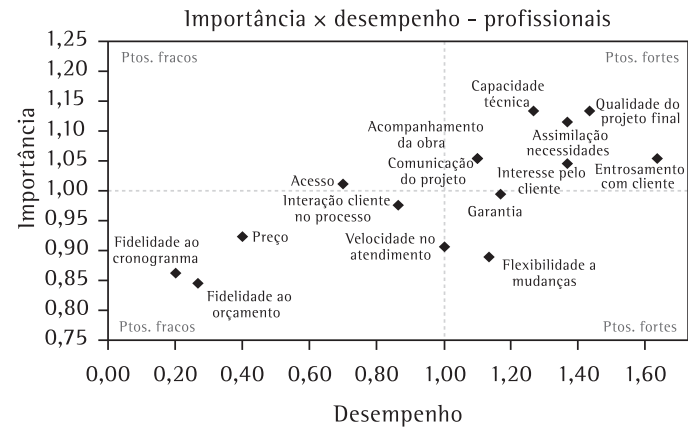

Figura 3. Matriz de importância e desempenho - Visão dos Profissionais.

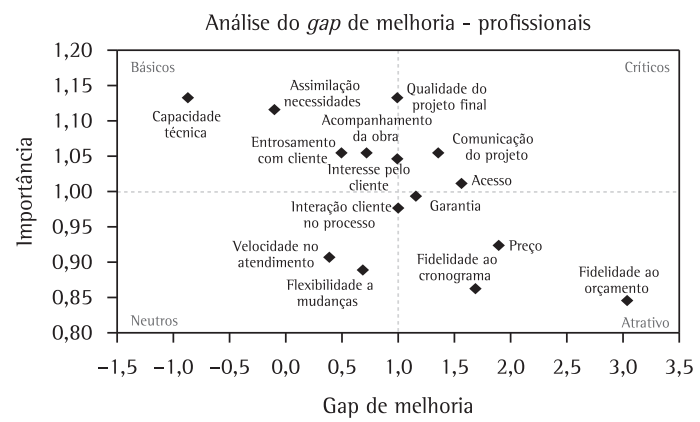

Figura 4. Análise dos gaps de melhoria - Visão dos Profissionais. superior em relação a "flexibilidade a mudanças" nos projetos e "velocidade no atendimento", mas pensam que os clientes consideram estes aspectos como de menor importância.

Devido ao fato dos atributos "acesso ao profissional" e "interação do cliente com o processo" terem importância intermediária e desempenho inferior, podemos dizer que, na visão dos arquitetos, estes aspectos merecem atenção.

0 atributo "garantia dos serviços" está bem próximo à linha divisória dos quadrantes, estando com importância média. Assim, consideraremos o atributo como sendo um ponto forte, na visão dos arquitetos. Desta maneira, "capacidade técnica", "qualidade do projeto final”, "assimilação das necessidades dos clientes", "interesse pelo cliente", "entrosamento com o cliente", "comunicação do projeto", "acompanhamento da obra” e "garantia” são considerados como pontos fortes pelos arquitetos. Os profissionais entendem que os clientes avaliam que têm menor desempenho em "fidelidade ao cronograma", "atendimento ao orçamento inicial" e em relação ao "preço", porém consideram que os clientes não dão tanta importância a esses aspectos.

A Figura 4 mostra a matriz de análise dos gaps de melhoria. Na visão dos arquitetos, os atributos básicos para o cliente são: "capacidade técnica", "assimilação das necessidades dos clientes", "entrosamento com o cliente", "interesse pelo cliente", "acompanhamento da obra" e "qualidade do projeto final". Devido aos atributos "garantia" e "interação com o cliente" terem importância mediana e um gap de melhoria também mediano, também os consideraremos como atributos básicos. Os atributos básicos, mesmo se melhorados, não trarão mais satisfação aos clientes, mas têm alta importância.

Já os atributos críticos para melhoria são "comunicação do projeto" e "acesso ao profissional". Os atributos "fidelidade ao orçamento", "preço" e "fidelidade ao cronograma" são considerados atrativos, isto é, se atendidos podem trazer um grande aumento na satisfação dos clientes. Os atributos "velocidade de atendimento" e "flexibilidade a mudanças" foram considerados como itens neutros. Para os arquitetos, os clientes dão baixa importância a esses atributos e, se melhorados, não trarão grande aumento em sua satisfação.

Comparando-se a análise de importância e desempenho (Figura 3) com a análise pelos gaps de melhoria (Figura 4), verifica-se que a maior diferença de interpretação está no atributo "comunicação do projeto". Este atributo é considerado um ponto forte na matriz de importância e desempenho, mas um ponto crítico na análise dos gaps de melhoria. 
Pode-se então dizer que, na visão dos arquitetos consultados na pesquisa, apesar de ser um ponto forte, esse atributo, se melhorado, tende a aumentar ainda mais a satisfação dos clientes.

\subsection{Atributos críticos de satisfação na visão dos clientes}

A Figura 5 mostra a matriz de importância e desempenho dos atributos na visão dos clientes. Os pontos fracos dos serviços de arquitetura, na visão dos clientes, são o "acompanhamento da obra" e a "garantia dos serviços". Segundo os clientes consultados, esses atributos são de alta importância, mas estão com desempenho inferior por parte dos profissionais.

Os clientes consideram de menor importância os atributos "comunicação do projeto", "interação do cliente com o processo" e "flexibilidade do arquiteto a mudanças no projeto". Para os clientes, estes atributos estão em nível adequado, mas não são tão importantes, constituindo-se em pontos fortes menores.

Como pontos fortes, os clientes consideram "qualidade final do projeto", "capacidade técnica dos profissionais", "entrosamento com o cliente", "assimilação das necessidades dos clientes" e "interesse do profissional". Já os atributos "fidelidade ao orçamento", "fidelidade ao cronograma”, "preço", "acesso ao profissional" e "velocidade no atendimento" são considerados como tendo menor desempenho, mas também de menor importância, sendo então classificados como pontos fracos menores.

A Figura 6 mostra a matriz de análise dos gaps de melhoria. Da mesma maneira que apontado pela análise de importância e desempenho (Figura 5), o "acompanhamento da obra" e a "garantia dos serviços" foram considerados atributos críticos para melhoria. Eles são considerados importantes pelos clientes e se melhorados tarão ganho na satisfação. Este resultado vai ao encontro do trabalho de Soetanto, Proverbs e Holt (2001), quando comentam que o critério com prioridade na necessidade de melhoria é a conclusão dos defeitos, ou seja, a garantia dos serviços.

Os atributos "qualidade do projeto final", "entrosamento com cliente", "capacidade técnica", "interesse pelo cliente" e "assimilação das necessidades" foram considerados básicos. Se tiverem seu desempenho aumentado, não trarão incremento de satisfação, porém são considerados de alta importância.

Os atributos "fidelidade ao orçamento", "fidelidade ao cronograma", "preço" e "acesso" são considerados atributos atrativos. Apesar de terem menor importância, na visão dos clientes, se melhorados, trarão aumento na satisfação, principalmente a "fidelidade ao

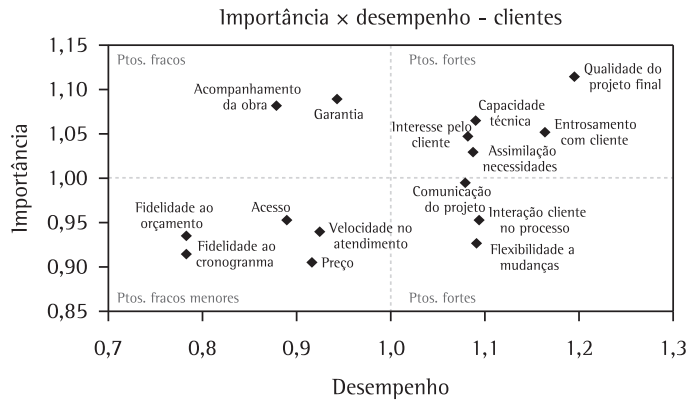

Figura 5. Matriz de importância $\times$ Desempenho - visão dos clientes.

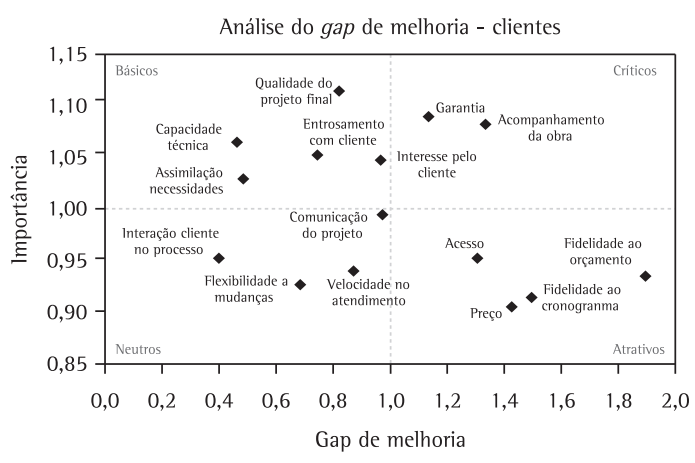

Figura 6. Análise dos gaps de melhoria - visão dos clientes.

orçamento". Os atributos "interação do cliente no processo", "flexibilidade a mudanças" e "velocidade de atendimento" foram considerados neutros.

0 atributo "comunicação do projeto" encontra-se em posição indefinida entre os quadrantes. Ele apresenta importância e gap de melhoria intermediários. Neste caso, classificá-lo-emos como um atributo básico, coincidindo parcialmente com a matriz de importância e desempenho.

\subsection{Comparando a visão dos clientes com a dos profissionais}

Uma comparação entre as matrizes de importância e desempenho na visão dos arquitetos e dos clientes (Figuras 3 e 5) mostram diferenças interessantes. Enquanto os profissionais consideraram "acesso" e "interação com o cliente" como aspectos do serviço a serem melhorados, os clientes consideraram como pontos fracos o "acompanhamento da obra" e a "garantia dos serviços". Os clientes também consideraram esses atributos como críticos na análise dos gaps de melhoria (Figura 6). Por outro lado, os arquitetos consideraram esses atributos como pontos fortes. 
Já comparando a análise pelos gaps de melhoria (Figuras 4 e 6), a visão entre arquitetos e clientes diverge quanto aos atributos "comunicação do projeto", "garantia”, "acesso" e "interação do cliente com o processo". Enquanto os profissionais consideraram "acesso" e "comunicação" como itens críticos, os clientes consideraram que "acesso" é um atributo atrativo e "comunicação do projeto" como básico. $\mathrm{Na}$ visão dos arquitetos, a melhoria da interação do cliente com o processo pode trazer ganho de satisfação, porém não é essa a visão dos clientes. Já no que diz respeito à "garantia", os clientes dão muito mais importãncia a este item do que os arquitetos imaginam.

A Tabela 1 mostra as diferenças de avaliação que profissionais e clientes fazem a respeito da importância dos atributos dos serviços de arquitetura. A significância das diferenças foi testada usando o teste U de Mann-Whitney (HOLLANDER; WOLFE, 1999). A base das diferenças de visão entre arquitetos e clientes está nas diferentes visões sobre quais necessidades o serviço deve satisfazer e qual a importância de cada atributo para os serviços prestados.

A Tabela 1 revela que, no que diz respeito à importância dos atributos, não há diferenças estatisticamente significativas entre os profissionais e clientes em quase todos os atributos. As diferenças estão nos atributos "fidelidade ao orçamento inicial", "garantia dos serviços prestados" e "assimilação das necessidades dos clientes". Os clientes consideram a "fidelidade ao orçamento original" e "garantia dos serviços" mais importantes do que os arquitetos imaginam.

Tabela 1. Diferenças na Imporância dos atributos para Clientes e Arquitetos.

\begin{tabular}{lcccc}
\hline & \multicolumn{4}{c}{ Importância } \\
\cline { 2 - 5 } & Profiss. & Clientes & Diferença & Signif. \\
\hline Acesso ao profissional & 4,14 & 3,94 & $-0,20$ & NS \\
Comunicação do projeto & 4,32 & 4,11 & $-0,21$ & NS \\
Entrosamento entre arquiteto e cliente & 4,32 & 4,35 & 0,03 & NS \\
Fidelidade ao cronograma inicial & 3,54 & 3,78 & 0,25 & NS \\
Fidelidade ao orçamento inicial & 3,46 & 3,87 & 0,40 & $*$ \\
Flexibilidade a mudanças & 3,64 & 3,83 & 0,19 & NS \\
Garantia dos serviços & 4,07 & 4,51 & 0,43 & $*$ \\
Interesse do arquiteto pelo cliente & 4,29 & 4,33 & 0,04 & NS \\
Interação do cliente c/ processo & 4,00 & 3,94 & $-0,06$ & NS \\
Assimilação necessidades cliente & 4,57 & 4,26 & $-0,31$ & $*$ \\
Qualidade do projeto final & 4,64 & 4,61 & $-0,03$ & NS \\
Capacidade técnica do profissional & 4,64 & 4,40 & $-0,24$ & NS \\
Valor cobrado (preço) & 3,79 & 3,74 & $-0,04$ & NS \\
Acompanhamento da obra & 4,32 & 4,47 & 0,15 & NS \\
Velocidade no atendimento & 3,71 & 3,89 & 0,17 & NS \\
\hline *Significante ao nivel de 90\% - Mann-Whitney U test. & &
\end{tabular}

Os artigos de Melhado et al. (2003), Winters (2003), Othmann, Pasquire e Hassan (2005) e Faulkner, Hudson e Barrett (2000) apontam o "programa de necessidades" como ponto-chave do desenvolvimento do projeto para atingir a satisfação do cliente. Esta é a mesma visão dos profissionais consultados, colocando o programa de necessidades em terceiro em ordem de importância. Já os clientes dão menos importância a "assimilação de necessidades". Essa menor importância dada pelos clientes pode residir no fato de eles confiarem na capacidade profissional do arquiteto e imaginarem que ele saiba coisas que eles não sabem sobre como deveria ser executado um projeto. Apesar de tecnicamente ser um atributo de extrema importância para o sucesso de um projeto, ele não é percebido pelos clientes. Este resultado coincide com o encontrado por Faulkner, Hudson e Barrett (2000).

A pesquisa comprova também o artigo de Soetanto, Proverbs e Holt (2001), que coloca o "valor cobrado pelo projeto" como sendo um atributo importante, mas não de extrema importância. Se tiver alto desempenho trará muita satisfação, mas caso não aconteça, não oferece insatisfação extrema ao cliente. E aqui fica comprovado que é um atributo atrativo para o Modelo KANO, e um ponto fraco menor, tanto na visão dos clientes como arquitetos.

\section{Considerações finais}

Com as mudanças no mercado educacional e a expansão de vagas nos cursos superiores no Brasil, o número de arquitetos concorrendo no mercado tem aumentado dramaticamente, mudando o perfil deste setor. Este artigo consiste em uma pesquisa exploratória e sua contribuição reside em trazer à luz a visão do cliente, em uma área em que, até há pouco tempo, a visão do fornecedor do serviço era soberana. Assim, o objetivo deste trabalho foi identificar a percepção dos clientes e dos arquitetos quantos aos atributos necessários à prestação de serviços vinculados aos escritórios de arquitetura.

Para os clientes, os atributos "acompanhamento da obra" e "garantia dos serviços" se mostraram como atributos críticos, corroborando com o artigo de Soetanto, Proverbs e Holt (2001), que também aponta a conclusão dos defeitos como ponto prioritário de necessidade de melhoria. A pesquisa mostrou também que "qualidade do projeto final", "assimilação de necessidades do cliente", "capacidade técnica", "entrosamento entre cliente e arquiteto" e "interesse pelo cliente" são atributos básicos para os clientes. Os artigos de Melhado et al. (2003), Winters (2003), Othmann, Pasquire e Hassan (2005) e Faulkner, Hudson e Barrett (2000) apontam o "programa de 
necessidades" como um atributo-chave para o sucesso de um serviço de arquitetura. A "qualidade do projeto final" também é abordada como ponto focal para satisfação dos clientes nos artigos de Cheng, Proverbs e Oduoza (2006), Faulkner, Hudson e Barrett (2000) e Melhado et al. (2003).

$\mathrm{Na}$ visão dos arquitetos, os atributos críticos são "comunicação - entendimento do projeto pelo cliente" e "acesso ao profissional". 0 resultado da pesquisa também mostrou que "flexibilidade", "entrosamento", "velocidade de atendimento", "programa de necessidades" e "capacidade técnica" são atributos obrigatórios na visão dos profissionais. Os atributos considerados básicos são "capacidade técnica", "assimilação das necessidades dos clientes", "entrosamento com o cliente", "interesse pelo cliente", "acompanhamento da obra", "qualidade do projeto final", "garantia" e "interação com o cliente".

$\mathrm{Na}$ visão tanto dos arquitetos quanto dos clientes, "fidelidade ao cronograma original", "preço" e "fidelidade ao orçamento original" são atributos atrativos, sendo que "fidelidade ao orçamento" é o atributo que mais poderia aumentar a satisfação dos clientes se atendido.

Os atributos "fidelidade ao orçamento inicial" e "garantia dos serviços" têm mais importância para os clientes do que os profissionais imaginam. Já o atributo "assimilação das necessidades" tem menos importância. As diferenças entre arquitetos e clientes sobre a importância dos atributos, revela que eles têm uma concepção diferente sobre o papel dos serviços prestados. 0 fato de "flexibilidade a mudanças" e "interação do cliente com o processo" terem sido classificados como neutros, e os atributos "garantia" e "acompanhamento da obra" como críticos pelos clientes, pode indicar que estes esperam que o arquiteto resolva o seu problema e consiga entender as suas necessidades (alta importância), sem necessidade de alterações ou interações posteriores. Isto corrobora as conclusões de Faulkner, Hudson e Barrett (2000). $\mathrm{Na}$ visão dos clientes, o serviço a ser prestado pelos arquitetos é um serviço técnico.

Por outro lado, o fato de, na visão dos arquitetos, o atributo "interação do cliente no processo" merecer maior atenção e ter maior capacidade de gerar satisfação nos clientes se melhorado, e que "comunicação e entendimento do projeto" e "acesso ao profissional" são pontos críticos de melhoria, indica que eles percebem que o serviço deve ser construído em conjunto com o cliente e que está mais concentrado na criação, no design, que na solução total dos problemas do cliente da criação até a obra final.
Como conclusão, levando em conta a visão dos clientes, o escritório de arquitetura que quiser ter um diferencial competitivo deve entender que seu serviço engloba desde a criação até a entrega da obra, com garantia dos serviços prestados. Que o cliente pressupõe que o arquiteto deve saber de suas necessidades e que o atendimento ao cronograma e orçamento iniciais são atributos atrativos.

\section{Referências}

BERGER, C. et al. Kano's methods for understanding customer-defined quality. Journal of the Japanese Society for Quality Control, v. 23, n. 2, p. 3-35, 1993.

BERRY, L. L.; PARASURAMAN, A. Serviços de marketing: competindo através da qualidade. Tradução de Beatriz Sidou. São Paulo: Maltese-Norma, 1992. 238 p.

CHENG, J.; PROVERBS D.; ODUOZA, C. The satisfaction levels of UK construction clients based on the performance of consultants. Engineering, Construction and Architectural Management, v. 13, n. 6, 2006. http://dx.doi. org/10.1108/09699980610712373

FAULKNER, A. J.; HUDSON, J.; BARRETT, P. S. Achieving exemplary quality in the construction professions. Structural Survey, v. 18, n. 4, p. 155-162, 2000 http://dx.doi.org/10.1108/02630800010341480

FORSYTHE, P. Modelling customer perceived service quality in housing construction. Engineering Construction and Architectural Management, v. 15, n. 5, p. 485-496, 2008. http://dx.doi.org/10.1108/09699980810902767

GIANESI, 1. N.; CORRÊA, H. L. Administração estratégica de serviços: operações para a satisfação do cliente. São Paulo: Atlas, 1996.

GIL, A. C. Métodos e técnicas de pesquisa social. 5. ed. São Paulo: Atlas, 2007. 208 p.

HOLLANDER, M.; WOLFE, D. A. Nonparametric Statistical Methods. 2. ed. Ney York: John Wiley, 1999.

HUISKONEN, J.; PIRTTILÄ, T. Sharpening logistics customer service strategy planning by applying Kano's quality element classification. International Journal on Economics, v. 56-57, p. 253-260, 1998.

INSTITUTO NACIONAL DE ESTUDOS E PESQUISAS EDUCACIONAIS - INEP. Censo da Educação Superior, 2001. INEP, 2001.

INSTITUTO NACIONAL DE ESTUDOS E PESQUISAS EDUCACIONAIS - INEP. Censo da Educação Superior, 2007. INEP, 2007.

KÄRNÄ, S. Analyzing customer satisfaction and quality in construction - the case of public and private customers. Nordic Journal of Surveying and Real Estate Research, Special Series, v. 2, p. 67-80, 2004.

KANO N. et al. Attractive quality vs must be quality. Journal of the Japanese Society for Quality Control, v. 14, n. 2, p. 39-48, 1984.

MARTILLA, J. A.; JAMES, J. C. Importance-performance analysis. Journal of Marketing, n. 9, p. 41-77, 1977.

MATZLER, K. et al. How to delight your customers. Journal of Product \& Brand Management, v. 2, p. 6-17, 1996. http://dx.doi.org/10.1108/10610429610119469 
MELHADO, S. B. et al. Implementação da gestão da qualidade em empresas de projeto. Ambiente Construído, v. 3, n. 1, p. 55-67, 2003.

MORGAN, R. E.; FOREMAN, S. K.; POH, T. C. C. Assessing the Status of marketing in Architectural Service Firms. Management Decision, v. 32, n. .4, p. 36-42, 1994.

MUNTING, P.; CRUYWAGEN, H. Quality management in South African architectural practices. Building and Environment, v. 43, n. 4, p. 444-452, 2008. http:// dx.doi.org/10.1016/j.buildenv.2006.09.001

OTHMANN, A. A. E.; HASSAN, T. M.; PASQUIRE, C. L. Analysis of factors that drive brief development in construction. Engeneering, Construction and Architectural Management, v. 12, n. 1, p. 69-87, 2005. http://dx.doi. org/10.1108/09699980510576907

PARASURAMAN, A.; ZEITHAML, V. A.; BERRY, L. L. A conceptual model of service quality and its implications for future research. Journal of Marketing, v. 49, n. 4, p. 41-50, 1985. http://dx.doi.org/10.2307/1251430

PICCHI, F. A. Sistemas de Qualidade: uso em empresas de construção de edifícios. 1993. Tese (Doutorado)Escola Politécnica da Universidade de São Paulo,São Paulo, 1993.

SAUERWEIN, E. Experiences with the Reliability and Validity of the Kano-Method: Comparison to Alternate Forms of Classification of Product Requirements. In: SYMPOSIUM ON QUALITY FUNCTION DEPLOYMENT - QFD, 1999, 11., Michigan. Proceedings... Michigan, 1999 p. 1-14.

SOETANTO, R.; PROVERBS, D. G.; HOLT, G. D. Achieving quality construction projects base don harmonious working relationships. International Journal of Quality \& Reliability Management, v. 18, n. 5, 2001. http://dx.doi. org/10.1108/02656710110392836

SYMES, M.; ELEY, J.; SEIDAL, A. D. Architects and Their Practices: A Changing Profession. London: Butterworths, 1995.

POWELL, C. Responding to marginalisation. Architectural Research Quarterly, v. 2, p.84-89, 1997.

TONTINI, G.; SANT'ANA, A. J. Identificação de Atributos Críticos de Satisfação em um Serviço Através da Análise Competitiva do Gap de Melhoria. Gestão e Produção, v. 14, p. 43-54, 2007. http://dx.doi.org/10.1590/S0104$530 \times 2007000100005$

TONTINI, G.; SILVEIRA, A. Identification of satisfaction attributes using competitive analysis of the improvement gap. International Journal of Operations \& Production Management, v. 27, n. 5, 2007. http://dx.doi. org/10.1108/01443570710742375

TORBICA, Z. M.;STROH, R. C. An Assessment Model for Quality Performance Control in Residential Construction. Journal of Construction Education, v. 4, n. 3, p. 332-340, 1999.

TORBICA, Z. M.; STROH, R. C. HOMBSAT - An Instrument for Measuring Home Buyer Satisfaction. Quality Management Journal, v. 7, n. 4, p. 32-44, 2000.

WINTERS, P. M. What owners want from architects - and how to ensure that expectations are met. Journal of Facilities Management, v. 2, n. 3, pp 276-284, 2003. http://dx.doi. org/10.1108/14725960410808258

\title{
Critical satisfaction attributes in architectural services: comparison of clients' and architects' points of view
}

\begin{abstract}
The purpose of the present work was to identify the perception of clients and architects on critical attributes of customers' satisfaction in services of home architecture. It is an exploratory and quantitative research which uses questionnaires to collect data. The 15 researched attributes were identified based on literature review. One hundred clients and thirty architects were interviewed. Results indicate that clients expect architects solve their problems from the design to the construction phases, and that they should understand customers needs without further changes and customers' interaction during the service process. In the clients' view, the service provided by the architects is technical. The architects believe their service should be carried out in close connection with clients and that the service is centered in the creation and design phases. As a conclusion, considering the clients view, the architects who want to have a competitive differential in the market should understand that their service has a wider scope, going from the creation until the handing in of construction, with guarantee of the services. Architects also must understand that clients suppose their needs are understood and that meeting the initial schedule and budget are attractive attributes.
\end{abstract}

\section{Keywords}

Service quality. Customer satisfaction. Architectural services. Project quality. 